\title{
Design and Management of Building's Resources
}

\author{
Ekaterina Sentova \\ Faculty of Architecture, University of Architecture, Civil Engineering and Geodesy, Sofia 1046, Bulgaria
}

\begin{abstract}
The developed modern control systems and buildings management resource systems would be effective if they are based on previously established optimal conditions during the building design. This is one of the key issues for a responsible architecture. The focus of this paper is on sustainable design methods and techniques for saving resources and their management throughout the building lifecycle. The main subject of the present article is the characteristics of these methods and their fundamental role in sustainable resource management during the building operation. The results which are based on conducted case studies of European and international practice in the construction of sustainable buildings are implemented here. Key features of a comprehensive approach for design and construction are outlined via comparative analysis, as well as various systems for the evaluation of sustainability for already constructed buildings. The mostly used criteria and indicators for sustainability are systematized, including those related to resource consumption. By analyzing a specific example, the role of sustainable design methods is justified as an important prerequisite for effective management of building resources in the process building maintenance. According to the conducted studies, during the longest life cycle period of a building, by implementation of control systems and resource management of building, the costs are successfully optimized. Specific directions that prove the effectiveness of such systems are systematized in the paper. Innovative approaches, complex methods and measures for design and management of buildings resources are presented as results of this study.
\end{abstract}

Key words: Sustainable design, sustainable buildings, BMS (Building Management System).

\section{Introduction}

In various fields of human activities, the concept of tangible and intangible resources is popular but traditionally five types of basic resources are used to work (concept 5M) [1]:

- man;

- money;

- materials and raw materials;

- machine and appliances;

- information and technologies.

In addition to the five elements, "time" as a special resource is also added.

A more detailed outline of resource types can be applied in the realization of a construction product, such as building, since their importance is of current interest for the architectural-building sector, as shown in Fig. 1. The scope of resources, object of specific analysis in this article, is in relationship with the topic

Corresponding author: Ekaterina Sentova, Ph.D., associate professor, research fields: industrial buildings and territory, sustainable architecture and sustainable design. E-mail: ksentova_far@uacg.bg. of sustainable and responsible architecture, in the context of principles and criteria for sustainable development of human communities and environment where they carry out their basic functions. As it is known, this topic includes interrelated and multiplied in time current questions on energy crises, climate changes, ecological pollution, reduction of life-supporting systems and resources on our planet, etc..

As the concepts for sustainable architecture and building developed, the scope of indicators for research, design and complete construction of habitat is increasingly expanding in a single aim - to maintain a balance between economic, social and ecological objectives. The focus of sustainable methods and approaches is primarily on the concern for non-renewable resources on the planet, for which reduction contributes particularly the building sector. According to conducted studies, $45 \%$ of population live in urban areas, on national level the building sector consumes about $40 \%$ of power, $40 \%$ of natural resources 


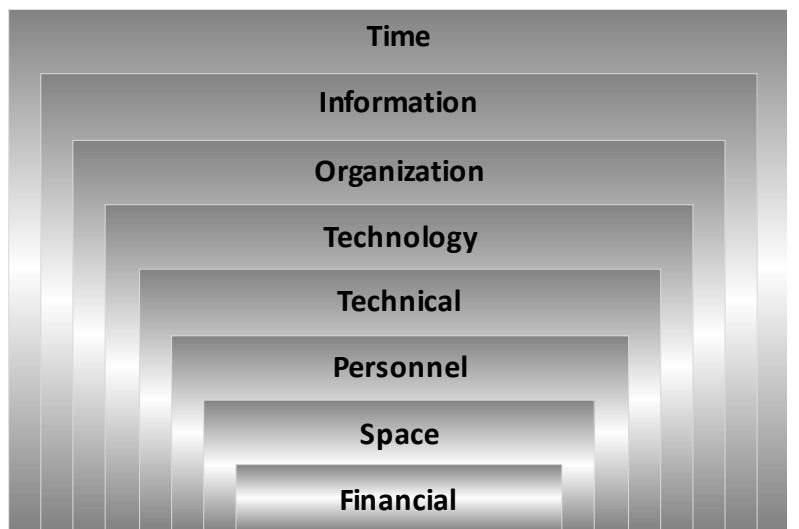

Fig. 1 Types of resources.

(primary products and materials) and produces $25 \%$ of the waste materials (in the process of building and demolition). Statistics of the International Energy Agency show that only buildings consume about 30\% of the final energy and are responsible for more than $40 \%$ of the greenhouse gas emissions worldwide [2].

All this is focusing the attention of professionals from various scientific fields related with building design, to create specialized products and design methods that can solve in complex the processes of effective resource management. Their work is focused on achieving the following goals:

- minimize the negative impact on environment and health of inhabitants;

- achieve energy efficiency and low operating costs;

- high quality of technical implementation;

- security and comfort.

\section{Sustainable Design as a Prerequisite for the Effective Management of Building Resources: Design Measures}

To design in a way that is in the context of the sustainability principles means to correlate produced and consumed resources from the urban ecosystem. This implies to recognize the interactions between natural and human resources and afterwards to create a holistic process between the project and the environment qualities for which it is intended - through management of energy resources, water, air and waste disposal [3].

The main prerequisite of achieving these sustainable features is the implementation of new complex approach for design and construction, with reference to the life cycle of the building. In the optimum state, the sustainability principles are embedded at design stage by an integrated design team because the opportunities for influence at an earlier stage are significantly larger than at the stage of completed project or finished building construction. In this way, the integral design saves huge costs and ensures long-term efficiency.

Studies have shown that the design of a sustainable building is a more complex process that starts with the design assignment and includes integration of sustainability criteria as well as during the design process as during every stage of construction works. The completed building is under observation for several months after its finishing and afterwards it is legislated by a quality certificate consisting again of an integrated system of criteria and indicators. These certificates play a multiple influence on the complete investment process according to the actual practice in various European countries.

The EU (European Union) supports and encourages consistently the sustainable construction by new common standards and directives for the member countries. In the international practice there are already several standards established, which are created moreover with the purpose to fulfill the basic principles in sustainable building construction. The world council of sustainable construction has recognized systems for evaluations of building sustainability: Green Star-Australia, LEED Canada ${ }^{\mathrm{TM}}$, German Sustainable Building Certification-Germany, IGBC Rating System \& LEED IndiaTM Green Building Rating Systems-India, CASBEE (Comprehensive Assessment System for Building Environmental Efficiency) - Japan, Green Star NZ-New Zealand, Green Star SA-RSA, BREEAM-UK, LEED Green Building Rating System ${ }^{\mathrm{TM}}$-USA [2]. According to the local building, cultural and social practices the 
evaluation systems provide a certificate for building sustainability. In LEED, BREEAM, DGNB and the other systems, the biggest load is concentrated on energy efficiency because it is the most substantial cost during exploitation in residential just as much as in industrial and public buildings. A building rated the most for concerning the diminished heat lost through the building cover, the optimization of heating and ventilation system, for passive sun benefit and energy efficiency of domestic appliances, fulfills the requirements for being awarded a certificate, which is presented in three degrees: silver, gold and platinum. If it is added to the reduced energy costs active methods for obtaining the rest of necessary energy by renewable energy resources, the building gains maximum opportunities to cover individually its energy demands that tend to be a requirement for the future new construction [2].

Studies have shown that the most widely spread systems are the British BREEAM, the American LEED and the Australian Green Star, as well the international project-Green Building Challenge, that includes initiators from 14 countries. Other popular systems with local importance are the French HQE, the German DGNB and the Japanese CASBEE, that go outside national boundaries and are implemented at the corresponding region [2].

Worldwide the last 20 years are a period of big development in creating and establishing systems of criteria for sustainable design and construction, among which an important place takes the indicators related with the consumption of resources. There are three basic directions of development - research-educational, design and those that are initiated from private, non-government organizations that create, organize and issue certificates in this field. The purpose of their activity is as to encourage best practices as to create enough comprehensive methods for monitoring and evaluation.

Criteria and indicators of building design are focused upon several major categories: location, energy and $\mathrm{CO}_{2}$ emissions, water, materials, waste, vegetation, pollution (by hazards), a healthy environment and health, effective management of building/home and adjacent land, ecology. The next step concerning each of categories is supposed to create a model developed in three phases: identifying features, their evaluation and development of an action program-i.e., programming of all actions with a specific strategy and measures of the project [3]. For example, the basic aims concerning water are generally related with:

- protection of surface water and mountain springs;

- collection and reuse of rainwater;

- maintaining an adequate level of water quality within the area and buildings;

- reducing the amount of treated water.

The specific design measures for reducing water consumption are multidirectional and include both levels - the interior and exterior space of building. As an example, systems are implemented to collect rain water that is reused for $\mathrm{WC}$ and irrigation, valves are mounted to reduce water pressure in taps, etc.. To maintain the water balance of the terrain before construction works is also part of the project sustainable measures. Otherwise, the groundwater level will change and disrupt ecosystems, and subsequently it will lead to difficulties in supply of clean drinking water. The measures in this regard are: design of minimum area with waterproof elements (paths, trails), planting local species, green roofs that collect rainwater in order to prevent lost to sewage drains. The overall interior equipment with devices for saving water continues to implement the complex measures and includes use of air batteries, energy efficient appliances, dishwashers, washing machines, etc.. An important stage of measures is specifically designed programmes to support the systems of all building installations. For this purpose, information brochures are developed containing instructions for maintenance of the various facilities during building exploitation. An essential part of the developed 
measures are the educational campaigns as well-in order to accelerate and enrich the culture of the inhabitants in terms of saving resources.

This general approach is applied to other categories and issues that are object of complex measures in the project for building resource-saving - for heating and ventilation, lighting, location, etc.. A complete coverage of the problems is achieved by designing on a method for assessing the life cycle of building, which the expenditure of resources is optimized concerning the full life cycle of building [3]. It follows the operation of all systems and components of the preliminary design studies, by the preparation of project documentation in all design and construction stages - through production of the materials, preparation for installation, transport, supply, construction execution, the period of building exploitation until its demolition when it is assessed again the suitability of materials for reuse or recycling.

As an answer to the common European directives for sustainable design and building construction, member states are expected to develop and implement their own measures for saving energy, use of renewable energy sources, reducing $\mathrm{CO}_{2}$ emissions, reducing water costs and improving water quality water, etc.. Thus, according to the European Directive on the energy building performance by the end of 2018, all public sector buildings of built area of over $250 \mathrm{~m}^{2}$ must have a near-zero carbon emission. After 2020, this requirement will apply to all new buildings at all, which means that it is necessary to urgently promote the methods for reducing dangerous emissions, and to train professionals in the implementation of new methods and approaches.

With the new European directives, a number of mandatory conditions are expected to be implemented in the sector for new construction:

- mandatory installation of photovoltaic panels;

- mandatory installation of solar thermal panels as to cover $50 \%$ of the needs for sanitary hot water;

- obligations for external sunscreen louvers for new buildings .

According to European directives, soon our buildings must meet certain regulatory requirements in the field of sustainable architecture and construction methods and approaches, like the leading practice in many EU countries. In countries like Denmark, Sweden, Netherlands, Germany and other, residential complexes and buildings have been built already, as well as buildings in the public sector, which comply with the technologies and criteria for sustainable construction and natural compliance and the results of their monitoring are encouraging $[3,4]$.

\section{BMS (Building Management System)}

A well-designed building, according to the principles of energy efficiency and responsible architecture, enables the management systems deployed in recent years in high-tech buildings to work effectively. BMS [5] is a system for monitoring and control, managed by main (central) computer which has a direct and complex impact on the cost of building resources. It is composed of intelligent end devices-programmable controllers, which include permanent memory, operating (RAM (Random Access Memory)) memory and microprocessor calculation of every transaction executed by the controller as well as I/O (input/output) components. Thus, the system provides information to the technical and managerial personnel and ability to influence all technical systems in the building by operator stations. BMS provides opportunity for:

- individual or multiple remote management and monitoring of air conditioning in premises that include: observation of current temperature, set temperature, start/stop convectors, heaters;

- remote control and monitoring of central air conditioning, covering emergency situations and the overall condition of equipment (pumps, refrigeration machines, centers and monitoring of temperatures collectors);

- monitoring of air quality $\left(\mathrm{CO}_{2}, \mathrm{CO}\right.$, humidity $)$ and 
management of ventilation on given levels;

- monitoring and management of other technological facilities (drainage pumps, pressure boosting pumps, etc.);

- lighting control - on schedule, on a preliminary conditions (lighting, on management sensors, on a program, etc.);

- monitoring and control of various subsystems - irrigation systems, blinds, advertisements, etc.;

- management and monitoring of electrical consumers, as well as instant energy user costs (electricity, water and fuel);

- monitoring and management of emergency generators, depending on the load and the condition of the main supply.

Additionally, it is monitored and information is received about the security and fire alarm systems as well as the access systems.

As a result of the BMS implementation, customers are availed the following opportunities:

- optimal allocation of resources (service workers, personnel staff, etc.); check system status at any time, complete overview of information at one place, which results in faster response and crisis management;

- management costs - water, electricity, fuel;

- constant monitoring of the various systems by a corresponding specialized staff;

- disclosure of current operational maintenance works.

In housing construction, there are also new technologies applied and their implementations are popular under the name "smart houses". A centralized management of systems is provided for heating, lighting, security systems, blinds and curtains, audio and video equipment, automation and synchronization is used between the domestic appliances and everything that is controlled electronically. All the house functions can be managed from a distance by the option allowing remote control. After leaving the house, all systems go to sleep mode, and thus drop consumption down to a minimum. In some European countries, this type of building houses is used by subsidies from the state because they are energy efficient and economical in terms of the overall cost of basic resources [6].

\section{Conclusions}

The topic of non-renewable resources, global environmental problems and causal relations with construction process and the whole construction sector is the focus of sustainable architecture and construction and their methods [7].

Studies of international practice show that the stress is on application and development of integrated approaches that aim comprehensive coverage and research of environmental, economic and social aspects of design and construction process [8]. In this course, the issues of saving resources are addressed in a wider context which includes analyzing impacts of buildings on the environment throughout their life cycle_planning, design, construction, operation and maintenance and deconstruction. This is achieved by integrated design teams. Application of specialized software for building analysis that addresses professional needs of different participants in the building design optimizes the design ideas in order to make optimal final decisions. The applied design and construction measures quality is proved by certificates for sustainability based on various certification systems for sustainability assessment.

The development and validation of systems for sustainability assessment in design and construction is a process that is constantly evolving and accredited worldwide. According to the conducted research, each state includes in its legal regulations specific requirements and conditions for sustainable development and applies buildings' certification as evidence that they meet the required criteria. Certification assessment systems are coordinated with the local building, cultural and social practices.

Buildings constructed according to the principles 
and criteria of sustainability provide a better opportunity for implementation of BMS which has a straight impact on building resources cost. Research results on constructed high-tech buildings equipped with such systems demonstrate clearly the benefits of their implementation $[4,5]$. The BMS is important for reducing the building resources' cost during its longest period of existence - the time of its operation.

The buildings have a long life - the usual time of operation exceeds the human lifetime. The choice of construction solution today will determine the life quality of its residents far ahead in time. Applying the principles of sustainable design must be consistent with the requirement for durability, easy and low cost of building maintenance. Quality system solutions ensure a longer warranty period and life as well as easier maintenance. Not addressing some issues at building design stage often results in much higher costs in order to correct them later. The selection of materials and systems is necessary to be considered not only in terms of price but also in regard of their exploitation time. The combination of design measures and quality systems for resource management affects significantly the financial results - reduction of operating costs of $30 \%-35 \%$ is achieved, while at the same time conducting control of appliances and equipment facilities to be in optimal regimes in order to preserve their resources. Finally, this helps to achieve the long-term goals of sustainability in the construction of living environment - to improve quality of life without increasing consumption of natural resources over the limit above which the environment cannot recover them, as not compromising the ability of future generations to meet their own needs.

\section{References}

[1] Resource Model System, Information Systems (C) Christo Tujarov, 2007, http://tuj.asenevtsi.com/Inf\%20sistem/ IS023.htm (accessed Feb. 23, 2012).

[2] Passive Buildings, Magazine for Construction, Architecture, Engineering, Construction Technologies And Materials Web Page, http://www.ka6tata.com/ energiina-efektivnost/pasivna-i-niskoenergiina-sgrada/arti cle/542 (accessed Apr. 11, 2012).

[3] G. Longhi, Guidelines for Sustainable Design, Officina Edizioni, Roma, 2003, pp. 67, 78, 92. (in Italian)

[4] E. Sentova, Sustainability principles and their application in architecture and construction-Harmonization with European standards, in: International Conference VSU'2005- “L. Karavelov" Civil Engeneering Higher School, Sofia, May 26-27, 2005, pp. 53-59.

[5] Building Management System (BMS), Enigma Ltd. Smart and Effective Security Solutions, http://www.enigmabg.eu/index.php?option $=$ com_content $\&$ view $=$ article \&id= 14\&Itemid=14\&lang=bg (accessed Apr. 10, 2012).

[6] Build Smart House Web Site, www.buildsmarthouse.com (accessed Feb. 24, 2012).

[7] CIB, Agenda 21 on Sustainable Construction, 1998, www.cibworld.nl (accessed Apr. 10, 2012).

[8] D. Nedyalkov, Ek. Sentova, The building design and resource saving as an element of sustainable architectural environment, in: Annual of the University of Architecture, Civil Engineering and Geodesy, International Conference, UACG'2009: Science and Practice, Sofia, Oct. 29-31, 2009, pp. 125-132. 